\title{
The revenge of the uneven trochee: Latin main stress, metrical constituency, stress-related phenomena and OT
}

\section{Haike Jacobs}

\section{Introduction}

Prince and Smolensky (1993) have provided an analysis of Latin stress which is based on Mester (1994) and which, by one and the same constraint hierarchy, provides an account of both the distribution of stress in Latin and the various stress-related shortening processes in Latin. Unfortunately, their analysis can be shown to be empirically incorrect. On the one hand, Mester's account of the facts is in need of modification, and on the other hand no account is provided for the stress-related syncope processes. Taking both facts into account it will be shown that Prince and Smolensky's analysis faces a number of theoretical and empirical problems. The purpose of this paper is to point out where the OT-analysis of Prince and Smolensky fails and to provide a more succesful OT-account of Latin stress and stress-related phenomena.

\section{Latin stress in Prince and Smolensky's account}

Mester (1994) has presented a number of arguments against a trimoraic or uneven trochee analysis of Latin stress. The first argument is based on two shortening processes termed iambic and cretic shortening. Iambic shortening occurs when a LH word becomes LL. Cretic shortening occurs when a word-final cretic HLH sequence is transformed in a HLL sequence. Iambic shortening also may apply word-internally, but then the condition is that the $\mathrm{H}$ syllable must be a closed syllable. That is, a syllable that is $\mathrm{H}$ because of a long vowel is not affected.

Mester argues that shortening crucially does not take place in words ending in a sequence $\mathrm{LLH}$ or $\mathrm{HH}$, which can in a moraic trochee analysis be exhaustively parsed as $(\mathrm{LL})(\mathrm{H})$ and $(\mathrm{H})(\mathrm{H})$ respectively, but only in cretic words which cannot be exhaustively parsed, but have a, what 
he calls, "trapped" medial syllable: $(\mathrm{H}) \mathrm{L}(\mathrm{H})$, as in, for instance dīc $\breve{t} \bar{o}$ $>$ dīcĭtŏ 'say (IMP.FUT)', and, in iambic words which can only be exhaustively parsed after shortening of the final H: LH > (LL), such

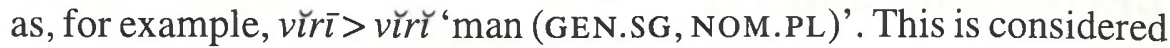
crucial evidence for a bimoraic and against a trimoraic analysis for Latin. A trimoraic analysis could also account for iambic shortening in LH words, but not for Cretic Shortening, given that HLH can be exhaustively parsed as $(\mathrm{HL})(\mathrm{H})$ under a trimoraic analysis.

Based on these observations, Prince and Smolensky (1993: 56-66) account for the Latin shortening processes (which manifested themselves in Pre-Classical, but not in Classical Latin) as a direct by-product of one basic parse. Shortened forms are among the candidates that are evaluated for $/ \mathrm{HLH} /$ and $/ \mathrm{LH} /$ inputs. That is, the optimal output for $\mathrm{HLH}$ is $(\underline{\mathrm{H}})(\mathrm{LH}-)$ and for LH it is ( $\underline{\mathrm{LH}}-)$, whereas for an HLL input the optimal output is $(\underline{\mathrm{H}})(\mathrm{LL})$ (main stress is indicated by underscoring; shortening by '-').

The following constraints are assumed, which are divided into three sets. (1a) presents the constraints responsible for the shape of the feet and ( $1 \mathrm{~b})$ gives the constraints responsible for the position and parsing of feet. The constraints in (1a) and (1b) were identical for Classical and Pre-Classical Latin. Finally, (1c) provides the position/parsing constraints that were ordered differently in the two periods.

\section{(1) a. FOOT FORM}

$\mathrm{Lx} \approx \mathrm{PR}: \mathrm{A}$ member of MCAT corresponds to a PrWD

FTBIN: Feet are binary at some level of analysis $(\mu, \sigma)$

RHTyPE (T): Rhythm type is trochaic

RHHRM or *(HL): Rhythmic harmony

b. POSITION/PARSING

NonFinality $(\underline{\mathrm{F}}, \underline{\sigma})>$ Edgemost $(\underline{\sigma}, \mathrm{R})$

because $(\underline{\mathrm{LL}})>\mathrm{L}(\underline{\mathrm{L}} \mathrm{L})$

No head of PrWd is final in PrWd (both head foot and head syllable) dominates the constraint that forces the main stressed syllable to be located at the right word edge.

Edgemost $(\underline{\sigma}, \mathrm{R})>>$ PARSE- $\sigma$

because $\mathrm{L}(\underline{\mathrm{LL}}) \mathrm{L}>(\underline{\mathrm{LL}})(\mathrm{LL})$ 
Parse syllables into feet is dominated by stressed syllable location.

$\operatorname{EdgemosT}(\underline{\sigma}, \mathrm{R}) \gg \mathrm{PK}-\mathrm{PROM}$

because HLLL $>$ HLLL

Stressed syllable location dominates $\underline{H}$ is a better peak than $\underline{L}$

c. SHORTENING vs. STABLE QUANTITY

WSP $>$ PARSE- $\mu$

because \#(LH-)\# $>$ \#(LH)\#

because $(\underline{\mathrm{H}})(\mathrm{LH}-) \#>\overline{\#}(\underline{\mathrm{H}})(\mathrm{LH}) \#$

Weight-to-Stress: heavy syllables are prominent in foot structure and on the grid dominates the constraint demanding moras to be parsed

PARSE- $\sigma \gg$ PARSE- $\mu$

because $(\underline{\mathrm{H}})(\mathrm{LH}-) \#>(\mathrm{H}) \mathrm{L}(\mathrm{H}) \#$

The ranking assumed for pre-Classical Latin is the one in (1c), where WSP $>>$ PARSE- $\sigma>>$ PARSE- $\mu$ has the effect of producing iambo-cretic shortening. In Classical Latin the ranking is changed into PARSE- $\sigma>$ PARSE- $\mu \gg$ WSP, which has the effect of creating stable quantity. For instance, an ouput $(a ́ m \bar{o})$ with a final long vowel will be evaluated better than (ámŏ) with a final shortened vowel, as a violation of the WSPconstraint is less important than fully parsing all moras. Similarly, dīc $(\underline{\mathrm{H}})(\mathrm{LH}-)$ with a final short vowel. The analysis thus adequately accounts for shortening in \#LH\# and -HLH\# cases.

Before pointing out some problems that occur when more shortening facts and when the syncope facts are taken into account, let us first notice that the analysis has no direct way for accounting for main stress. Sometimes main stress is on the final foot as in L(LL)L, (LL)L, $(\mathrm{H}) \mathrm{L}$ or (LL) cases, but other times on the prefinal foot: as in $(\underline{H})(\mathrm{LL})$ and $(\underline{H})(\mathrm{LH})$ cases. In general it is either the last or the first foot that receives main stress in languages. The End Rule of previous derivational theories is specifically designed to promote the first or last foot to main stress. Hayes' (1995) End Rule final/initial has been translated in OT terms in a more general way than EDGEMOST in (1b) above. McCarthy 
and Prince (1993) propose the constraint ALIGN-HEAD which demands that the left or right edge of the Prosodic Word is aligned with the left or right edge of the head of the Prosodic Word (i.e. its main stressed foot). Kager (1999) proposes the constraints RIGHTMOST and LEFTMOST (cf. Kager 1999), which demand that the head-foot be final or initial. It is clear that in the analysis proposed by Prince and Smolensky, these constraints have to be dominated by NonFINALITY in order to get main stress on a prefinal foot. We will show below that these constraints together predict quarternary stress systems, which do not exist. The reason why Prince and Smolensky make reference to both the stressed syllable and the stressed foot in the constraint NoNFINALITY is clear. In an LH-word the optimal parse must be $(\underline{\mathrm{LH}})$ in Classical and (LH-) in Pre-classical Latin (the ámō versus ámŏ example given above), instead of either $\mathrm{L}(\mathrm{H})$ or $(\mathrm{LH})$. If no reference to the stressed syllable were made, $\mathrm{L}(\underline{\mathrm{H}})$ would be better than $(\underline{\mathrm{L}} \mathrm{H})$. Both violate NonFinality of the stressed foot and $\mathrm{L}(\underline{\mathrm{H}})$ would not, contrary to $(\underline{\mathrm{LH}})$ violate WSP. The candidate $(\underline{\mathrm{LH}})$ wins because it has only one violation of NonFinaliTY: only the stressed foot is final, but not the stressed syllable. Reference to the stressed foot in NoNFinality is necessary in order to achieve the effect of exhaustive parsing/footing of post-main stressed syllables.

Additional problems show up when we consider more empirical facts. Let us first consider shortening. As mentioned above, Mester crucially excludes cases of shortening in words of the form LLH\# or

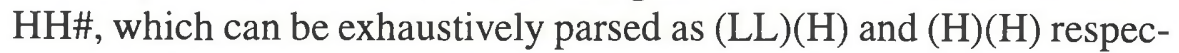
tively, but not in cretic words which cannot be exhaustively parsed and have a so-called "trapped" medial syllable: $(\mathrm{H}) \mathrm{L}(\mathrm{H})$, nor in iambic words which can only be exhaustively parsed after shortening of the final $\mathrm{H}$ : $\mathrm{LH}>(\mathrm{LL})$. However, there seems to be no reason to believe that shortening did only apply to iambic or cretic words and did not affect other heavy final syllables. Niedermann (1931: 71-72) and Lindsay (1894: 207-208) state that there is a tendency to shorten every long vowel in a final syllable. Niedermann (1931:71-73) provides some crucial examples involving sequences LLH and HH, such as ănĭmăl (GEN animālis) 'living being,' calcăr (GEN calcāris) 'spur,' lictŏr (GEN lictōris) 'lictor,' and light scansions of the final $\mathrm{H}$ in the same sequence in examples from Terence and Ennius, such as, mandēbăt 'to chew 
(IMP.3SG),' audīrĕt 'to hear (IMP.3SG)' and cantŏ 'to sing (PRES. I SG)' (cf. Lindsay, 1894: 207). Benloew (1847: 180) gives some more examples, such as, sermŏ 'conversation,' pulmŏ 'lung,' amb̆ 'both.' It goes almost without saying that the constraint-based analysis summarized in (1) above cannot handle the cases of shortening in LLH\# and $\mathrm{HH} \#$ words, because $(\underline{L L})(\mathrm{H})$ will be evaluated better than $(\underline{L L})(\mathrm{H}-)$ and $(\underline{\mathrm{H}})(\mathrm{H})$ better than $(\underline{\mathrm{H}})(\mathrm{H}-)$.

Second, the analysis cannot account for syncope in HLH\# and HLL\# cases where the targeted vowel (indicated by boldface) is in the strong position of the foot: $(\underline{H})(\mathbf{L H})(\underline{H})(\mathbf{L L})$. Although in the first case we might compare or evaluate, for instance, an $(\underline{\mathrm{H}})(\mathrm{H})$ output with an $(\underline{\mathrm{H}})$ (LH-) ouput for an /HLH/ input and thus consider either output as a way of exhaustive parsing of an /HLH/ input, this cannot be done in other cases where syncope applied. Mester (1994), basing himself on Lindsay (1894: 173), states that Early syncope (Preclassical and Classical Latin) is restricted to cases where HLH becomes $\mathrm{HH}$, as in for

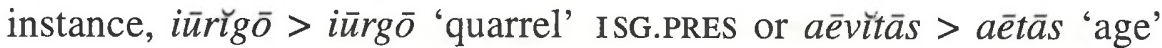
NOM.SG, which is considered another way of resolving a medial trapped syllable. Crucially Mester claims that syncope does not apply to LL feet. Mester concludes (1994: 43): "as a process predominantly affecting post-tonic light syllables stranded between heavy syllables, it receives a natural interpretation in a strictly bimoraic theory as a way of resolving trapping situations." However, Lindsay (1894: 170-173;178185) offers a more precise description, and distinguishes between Early, Classical, and Late Latin syncope. Early syncope took place when main stress was still on the initial syllable ("The old accent law" Lindsay 1894: 178-181). Classical syncope occurred when main stress was either on the penult or antepenultimate syllable ("syncope under the Paenultima Accent Law" Lindsay 1894: 183-185). With respect to Early syncope he states "it seems to have been the law of Early Latin that $\check{e}$ and $\breve{i n}$ the syllable after the accent always suffered syncope . . . The Early Latin accent fell on the first syllable of each word, so that every $\breve{l}$ and $\check{e}$ in a second syllable not long by position must have suffered syncope." Some examples involving syncope in LL (initial and post-tonic) sequences based on Niedermann (1931) and Lindsay (1894) are pěrǐstróma > perstroma 'bedspread,' frigdaria 'refreshing' beside frĭgìdus 'cold,' caldarius 'room for hot baths' beside călĭdus 'hot', 
'warm' all from Lucilius (second century BC), and, mॉntsterium > minsterium, misterium 'function, task' from Plaute (third/second century BC) show the application of syncope in LL sequences. A somewhat larger list is given in (2).

$\begin{array}{lll}\text { (2) ăvǐcaps } & >\text { aucaps } & \text { 'bird catcher' } \\ \text { lāmĭnă } & >\text { lamna } & \text { 'metal plate' } \\ \text { prŏpĭter } & >\text { propter } & \text { 'nearby', 'because of' } \\ \text { răvĭcus } & >\text { raucus } & \text { 'raucous', 'hoarse' } \\ \text { sŏlĭdus } & >\text { soldus } & \text { 'solid' (Lex Municipalis, J. Caesar) } \\ \text { ŭlĭna } & >\text { ulna } & \text { 'arm' } \\ \text { jūgěra } & >\text { jugra } & \text { 'field' (Lex Agraria Thorius, III BC) } \\ \text { compŏsĭtus } & >\text { compostus } & \text { 'to put together p.p.' } \\ \text { pŏsĭtus } & >\text { postus } & \text { 'to place p.p.' } \\ \text { bārĭca } & >\text { barca } & \text { 'barque' } \\ \text { pŏsı̆no } & >\text { pono } & \text { 'to place I sG' } \\ \text { ălĭter } & >\text { alter } & \text { 'the one', 'the other' } \\ \text { călěfacere } & >\text { calfacere } & \text { 'to heat' Quintilian (I AD) } \\ \text { ŏlěfacere } & >\text { olfacere } & \text { 'to smell' } \\ \text { pŏtěsum } & >\text { possum } & \text { 'to be able I sG' } \\ \text { fěrĭme } & >\text { ferme } & \text { 'almost' } \\ \text { vălĭde } & >\text { valde } & \text { 'very', 'strongly' }\end{array}$

The forms in (2) show abundant application of syncope to LL feet. Given that syncope applies within a foot, it cannot be stated as "a process predominantly affecting post-tonic light syllables stranded between heavy syllables" and, hence, obviously cannot be adduced as evidence for strict bimoraicity in Latin. Given that syncope both applies to word-inital HL- and LL- sequences, as the forms in (2) show, Lahiri, Riad and Jacobs (1999) describe syncope as providing evidence for a quantity-sensitive (uneven trochee) main stress foot and as a foot-based process able to affect all post-tonic (that is, both after secondary stress and after main stress) light syllables.

To summarize, an adequate OT-analysis of Latin stress and stressrelated phenomena should account for both syncope and shortening as direct results of one and the same parse or constraint hierarchy. Let us 
restate the two main problems for Prince and Smolensky's OT-analysis discussed in this section. First, reference must be made to the foot with main stress in the constraint NoNFINALITY, which as we will argue below, predicts the existence of nonexisting quarternary stress systems. Second, the analysis cannot account for all cases of shortening nor for syncope in LL-sequences. In the next section we will provide a modified account that is not thwarted by the same problems.

\section{A unified OT-account of Latin stress and stress-related phenomena}

\subsection{Main stress}

Let us start with the main stress problem. It is clear that by demanding that the head foot must not be final, an output $(\mathrm{H})(\mathrm{LL})$ will be favored over an output $(\mathrm{H})(\underline{L} L)$ for an HLL input. The implicit idea here is that any foot in an ouput candidate can possibly be the one with main stress. Comparing a number of different candidates against the constraint hierarchy will result in selecting the optimal candidate. As mentioned above, this implies that the constraint responsible for main stress Edgemost or alignment constraints such as Align-Head (McCarthy and Prince 1993) or Rightmost (Align Head-Foot, R, PRWD, R) or Leftmost (Align Head-Foot, L, PrWd, L) (cf. Kager 1999), which demand that the head-foot be final or initial and which are OT-translations of Hayes' (1995) End Rule final/initial must be dominated by the constraint NonFinality. As shown in (1b) EdGEMOST dominates PARSE- $\sigma$. However, if PARSE- $\sigma$ is reranked above NonFinality and Edgemost, a quarternary stress system is predicted, as shown in (3). Quarternary stress systems do not exist, although a quarternary pattern sometimes does occur in languages (cf. Jacobs (1999) for a more detailed account). In (3) we assume right-toleft footing (expressed by high ranked ALIGN-FT-R (every foot must be right-aligned with the right edge of the Prosodic Word)). Furthermore, for clarity's sake, we have considered a quantity-insensitive stress system. 


\begin{tabular}{|c|c|c|c|c|c|}
\hline (3) & $\sigma \sigma \sigma \sigma$ & PARSE- $\sigma$ & NonFIn $\left(F^{\prime}\right)$ & Al-Ft-R & EDGEMOST \\
\hline & $(\underline{\sigma} \sigma)(\sigma \sigma)$ & & & $\sigma \sigma$ & $\sigma \sigma \sigma$ \\
\hline & $\sigma(\underline{\sigma \sigma}) \sigma$ & $* ! *$ & & $\sigma$ & $\sigma \sigma$ \\
\hline & $(\underline{\sigma \sigma}) \sigma \sigma$ & $* ! *$ & & $\sigma \sigma$ & $\sigma \sigma \sigma$ \\
\hline & $(\sigma \sigma)(\underline{\sigma \sigma})$ & & $* !$ & $\sigma \sigma$ & $\sigma$ \\
\hline 膤 & $\sigma(\underline{\sigma \sigma} \sigma)(\sigma \sigma)$ & $*$ & & $\sigma \sigma$ & $\sigma \sigma \sigma$ \\
\hline & $(\underline{\sigma \sigma}) \sigma(\sigma \sigma)$ & $*$ & & $\sigma \sigma \sigma !$ & $\sigma \sigma \sigma \sigma$ \\
\hline & $\sigma(\sigma \sigma)(\underline{\sigma \sigma})$ & $*$ & $* !$ & $\sigma \sigma$ & $\sigma$ \\
\hline & $(\sigma \sigma)(\underline{\sigma \sigma}) \sigma$ & $*$ & & $\sigma \# \sigma \sigma \sigma !$ & $\sigma \sigma$ \\
\hline 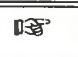 & $(\bar{c}(\sigma \sigma)(\underline{\sigma \sigma})(\sigma \sigma)$ & & & 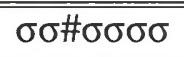 & $\overline{\overline{\sigma \sigma \sigma \sigma}}$ \\
\hline & $(\sigma \sigma)(\sigma \sigma)(\sigma \sigma \sigma)$ & & $* !$ & $\sigma \sigma \# \sigma \sigma \sigma \sigma$ & $\sigma$ \\
\hline & $\sigma(\sigma \sigma)(\sigma \sigma \sigma) \sigma$ & $* ! *$ & & $\sigma \# \sigma \sigma \sigma$ & $\sigma \sigma$ \\
\hline
\end{tabular}

If we simply omit reference to the main stressed foot in the constraint NonFinaliTy, the unattested quarternary systems will no longer be possible (cf. Jacobs 1999) and main stress in Latin will always be on the last foot, as we will show next. ${ }^{1}$ The constraints we assume are listed in (4).

(4) Position/Parsing
a. NonFinality: A foot may not be final
b. Align (PRWD, R, FT, R)
c. PARSE- $\sigma$
d. WSP

Constraint (b) is essentially similar to EDGEMOsT, although we will show below that there is, in fact, a difference between the two. Constraints (c) and (d) are identical to the ones in (1). The constraints in (4) (and with NonFINA LITY doubly simplified) will always yield main stress on the final foot, as we will show now. A foot will never be final except under compulsion of the higher ranked constraint: FTBIN. This accounts for monosyllabic words. This also means that $\mathrm{HH}$ will be optimally parsed as $(\underline{\mathrm{H}}) \mathrm{H}$ and not as $(\underline{\mathrm{H}})(\mathrm{H})$, given that the parsing of the final syllable (which avoids a violation of PARSE- $\sigma$ ) results in a 
violation of the higher-ranked modified NonFinality constraint, as illustrated in (6c) below. A bisyllabic input $\mathrm{LH}$ will still be $(\mathrm{LH})$ and not $(\underline{\mathrm{L}}) \mathrm{H}$ which violates FTBIN. Both $\mathrm{L}(\underline{\mathrm{H}})$ and $(\underline{\mathrm{LH}})$ violate NonFINALITY, but ( $\underline{\mathrm{LH}}$ ) will be evaluated better, given that, although it violates WSP, it avoids a violation of PARSE- $\sigma$ ranked above WSP, as shown in (6b) below.

Furthermore, we will leave the Foot Form constraints in (1a) unaltered except crucially for the constraint banning the uneven trochee: *(HL) (cf. Prince and Smolensky 1993). We assume that this constraint in Latin is dominated by PARSE- $\sigma$. This will give us the constraint ranking in (5).

(5) Undominated: Lx $\approx$ PR, FTBIN, RhTyPE (T)

Crucially ranked:

NonFIN $>>$ ALIGN $($ PRWD,R,FT,R) $>>$ PARSE- $\sigma>$ WSP $>*(\mathrm{HL})$

The constraint ranking in (5) implies that HLL will optimally be (HL)L, and that HLH will be optimal if (HL)H, as illustrated in (6e) and (6d). The joint effect of these modifications (NoNFINALITY simplified (neither reference to main foot nor to stressed syllable) and *(HL) dominated by PARSE- $\sigma$ ) will result in main stress being located always on the last foot.

In (6a-e) we have listed several tableaux for relevant parsings, where the top three constraints of (5) are collectively listed as FTFORM and where for clarity's sake we have marked the stressed syllable for every foot. Also every foot in the ouput candidate is evaluated. The optimal candidates resulting from the different inputs are considered to be formal Classical Latin forms, where no syncope or shortening has applied. 


\begin{tabular}{|c|c|c|c|c|c|c|}
\hline (6) & 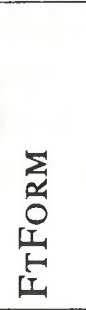 & $\begin{array}{l}\text { Z } \\
\text { 至 } \\
\mathbf{Z} \\
\text { o } \\
Z\end{array}$ & 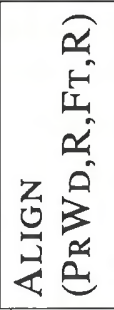 & 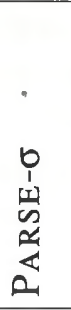 & $\frac{0}{3}$ & $\underset{*}{\underbrace{\ominus}_{*}}$ \\
\hline a. $/ \mathrm{HL} /$ & & $* !$ & & & & * \\
\hline$\leftrightarrow(\underline{\mathrm{H}}) \mathrm{L}$ & & & $\sigma$ & * & & \\
\hline $\mathrm{H}(\underline{\mathrm{L}})$ & $* !$ & $*$ & & * & $*$ & \\
\hline$(\mathrm{HL})$ & $* !$ & $*$ & & & $*$ & \\
\hline b. $/ \mathrm{LH} /$ & $* !$ & & $\sigma$ & ** & * & \\
\hline$(\underline{\mathrm{LH}})$ & & $*$ & & & $*$ & \\
\hline $\mathrm{L}(\underline{\mathrm{H}})$ & & $*$ & & $* !$ & & \\
\hline$(\mathrm{L} \underline{\mathrm{H}})$ & $* !$ & $*$ & & & & \\
\hline c. $/ \mathrm{HH} /$ & & *! & & & & \\
\hline$\Leftrightarrow(\underline{\mathrm{H}}) \mathrm{H}$ & & & $\sigma$ & $*$ & $*$ & \\
\hline $\mathrm{H}(\underline{\mathrm{H}})$ & & $* !$ & & * & $*$ & \\
\hline$(\mathrm{H} \underline{\mathrm{H}})$ & $* !$ & $*$ & & & & \\
\hline d. $/$ /HLH/ & & *! & T & * & ** & \\
\hline$(\underline{\mathrm{HL}}) \mathrm{H}$ & & & $\sigma$ & * & $*$ & $*$ \\
\hline$(\underline{\mathrm{H}}) \mathrm{L}(\underline{\mathrm{H}})$ & & $* !$ & & * & & \\
\hline$(\underline{\mathrm{H}}) \mathrm{LH}$ & & & $\sigma \sigma !$ & $* *$ & $*$ & \\
\hline $\mathrm{H}(\mathrm{L} \underline{\mathrm{H}})$ & $* !$ & $*$ & & * & $*$ & \\
\hline$(\underline{\mathrm{HL}})(\underline{\mathrm{H}})$ & & $* !$ & & & & $*$ \\
\hline e. $/ \mathrm{HLL} / \quad(\underline{\mathrm{H}}) \mathrm{LL}$ & & & $\sigma \sigma !$ & $* *$ & & \\
\hline 膤 $(\underline{\mathrm{HL}}) \mathrm{L}$ & & & $\sigma$ & $*$ & & $*$ \\
\hline $\mathrm{H}(\underline{\mathrm{LL}})$ & & $* !$ & & * & $*$ & \\
\hline$(\underline{\mathrm{H}}) \mathrm{L}(\underline{\mathrm{L}})$ & $* !$ & $*$ & & $*$ & & \\
\hline$(\underline{\mathrm{H}})(\underline{\mathrm{LL}})$ & & $* !$ & & & & \\
\hline$(\mathrm{HL})(\underline{\mathrm{L}})$ & $* * !$ & $*$ & & & $*$ & $*$ \\
\hline
\end{tabular}


The constraint hierarchy assumed thus far incorrectly predicts main stress in LHL words, as shown in tableau (7).

\begin{tabular}{|c|c|c|c|c|c|c|c|}
\hline (7) & /LHL/ & 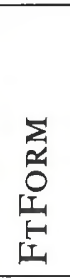 & $\begin{array}{l}z \\
\frac{1}{n} \\
0 \\
z \\
z\end{array}$ & 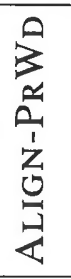 & 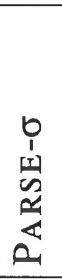 & $\begin{array}{l}\tilde{y} \\
\vdots\end{array}$ & $\underset{*}{\stackrel{\theta}{\Theta}}$ \\
\hline a. & $\overline{\mathrm{L}(\mathrm{HL})}$ & & *! & & * & & * \\
\hline b. & (LH)L & & & $\sigma$ & * & * & \\
\hline c. & $(\underline{\mathrm{L}}) \mathrm{H}(\underline{\mathrm{L}})$ & & *! & & * & * & \\
\hline d. & (L)HL & $* !$ & & $\sigma \sigma !$ & ** & * & \\
\hline e. & $\mathrm{L}(\underline{\mathrm{H}}) \mathrm{L}$ & & & $\sigma$ & $* *$ & & \\
\hline
\end{tabular}

Candidate (7b) is better than either candidate (7a) or (7e) which both have main stress on the correct syllable. If we disregard (7a) which violates NonFinality, then it is clear that (7b) is better than (7e) because of the relative ranking of PARSE- $\sigma$ and WSP. It should be noticed also, that under the old constraint Edgemost $(\underline{\sigma}, \mathrm{R})$, candidate (7e), which we actually want to be the optimal one, would be preferred over candidate (7b). Now, if we look back at the tableaux in (6) we can see that the only case where this ranking is crucial is in $\mathrm{LH}$-words. If the ranking was inverted the optimal output for an /LH/-input would be $\mathrm{L}(\underline{\mathrm{H}})$ instead of $(\underline{\mathrm{L}})$.

To get main stress on the correct syllable in these /LHL/ cases, we could specifiy for the constraint (4b), which aligns the right-edge of the Prosodic Word with a foot, that alignment should take place with a quantity-sensitive foot. At first sight, this might seem useful as it opens a way of accounting for mixed stress systems, where quantity-sensitivity is restricted to the last foot, but where secondary stresses are expressed by quantity-insensitive feet. For Latin, we could specify that the left edge of a Prosodic Word is aligned with a quantity-insensitive foot, and the right edge of a Prosodic Word with a quantity-sensitive foot. However, there are two main problems with such an approach. First, for the specific /LHL/ case this still does not solve the problem, because it is 
not clear whether the foot in ( $\underline{\mathrm{LH}}) \mathrm{L}$ must be considered a quantitysensitve foot. If ( $\underline{\mathrm{LH}}$ ) for an \#LH\# word is considered to be one (cf. (6b)), ( $\mathrm{LH}) \mathrm{L}$ in /LHL/ should be one too, which means that we still cannot force /LHL/ to become $\mathrm{L}(\mathrm{H}) \mathrm{L}$. Second, the fact that secondary stress is insensitive to quantity, whereas main stress is sensitive should be expressed by the constraint hierarchy itself (i.e. by the relative ranking of WSP with respect to the Alignment constraints ALIGN (PRWD, R, FT, R) and Align (PRWD, L, FT, L).

Suppose next that a constraint is added which simply prevents a heavy penultimate syllable from being skipped. Although this brute force solution seems to be able to do the job, and, also accounts for the fact that in Latin the penultimate syllable was the only syllable where weight mattered for stress distribution (a situation which remained largely intact in most of the contemporary Romance languages), it is not a very attractive one, because it is a rather clumsy expression of the fact that only the last foot in Latin was sensitive to quantity.

In order to get main stress on the correct syllable in these LHL-cases we have to rank WSP above PARSE- $\sigma$. This is illustrated in (8).

\begin{tabular}{|c|c|c|c|c|c|}
\hline /LHL/ & 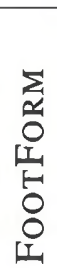 & $\begin{array}{l}\mathbf{Z} \\
\text { 竞 } \\
\mathbf{Z} \\
0 \\
\mathbf{Z}\end{array}$ & 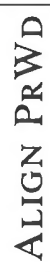 & $\begin{array}{l}\vec{n} \\
3\end{array}$ & 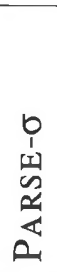 \\
\hline $\mathrm{L}(\underline{\mathrm{HL}})$ & & $* !$ & & & $*$ \\
\hline$(\underline{\mathrm{LH}}) \mathrm{L}$ & & & $\sigma$ & $* !$ & $*$ \\
\hline$(\mathrm{LH}) \mathrm{L}$ & $* !$ & & $\sigma$ & & * \\
\hline 吗 $\mathrm{L}(\mathrm{H}) \mathrm{L}$ & & & $\sigma$ & & $* *$ \\
\hline
\end{tabular}

In (9) we summarize the rankings: 
(9) Undominated: $\mathrm{Lx} \approx \mathrm{PR}$, FTBIN, RhTyPe (T), Crucially:

NONFIN $\gg$ ALIGN (PRWD,R,FT,R) $\gg$ WSP $>$ PARSE- $\sigma \gg$ $*(\mathrm{HL})$

Simplifying NonFinAliTY and tolerating the uneven trochee as a constituent, not as a primitive foot-type but one resulting from constraint interaction permits an account of Latin main stress which does not lead to the predicted existence of unattested stress systems (i.e. quarternary ones). Moreover, it receives independent motivation as it is necessary to account for Latin syncope, which we will demonstrate in the next section.

\subsection{Syncope and vowel shortening}

In order to account for vowel shortening and vowel syncope, we assume the constraints in (10).
a. *VV\#
Avoid a long vowel in final position
b. *V IN (x.) Avoid a Vowel in the weak position of a foot
c. PARSE-V Parse underlying Vowels
d. WSP
Heavy syllables are prominent in foot structure and on the grid

It should be noted that the constraint (10b) which is going to be responsible for syncope is similar to Loehken's (1997) *PL $\left(\sigma_{\mathrm{w}}\right)$ ("Vokale in unbetonten Silben haben keine Ortsmerkmale") or to Kager's (1997) REDUCE (Weak syllables dominate no vocalic features). A ranking PARSE-V, WSP $>$ *VV\#, *V IN (x.) accounts for stable quantity and no syncope, whereas a ranking *VV\#, *V IN (x.) > PARSE-V, WSP accounts for both syncope and shortening. The former ranking is assumed for Classical Latin and the latter for Pre-Classical and Late Latin. It might be more precise, given the optional nature of the processes, to say that for the periods before and after Classical Latin, the constraints in (10) would either be floating or crucially non-ranked. A complete overview of the ranking assumed thus far is given in (11). 


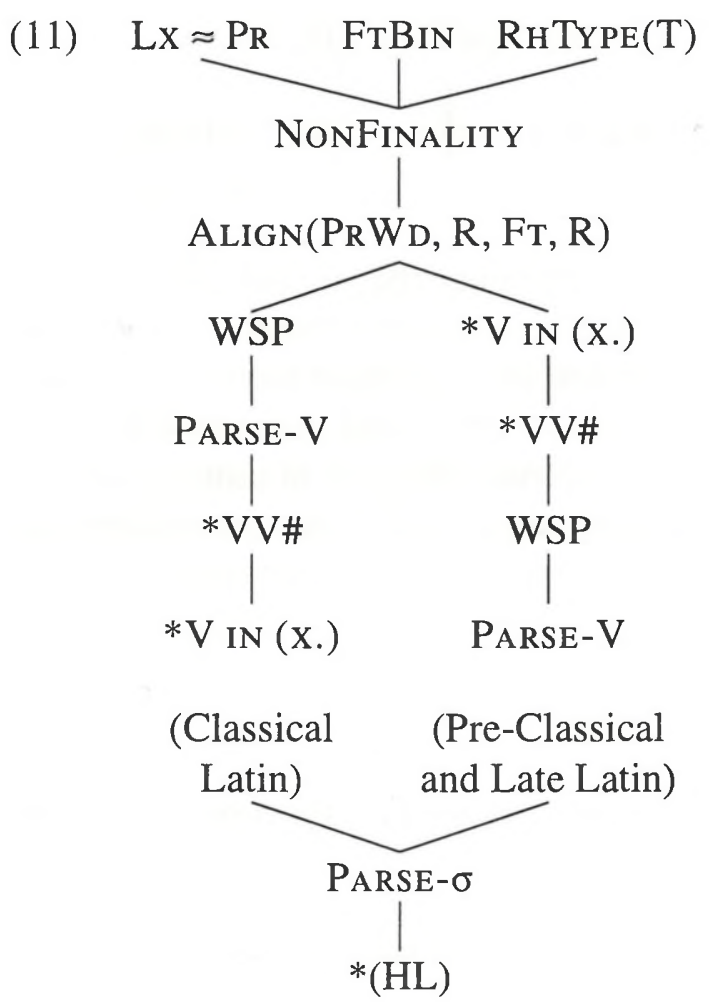

In (12) we compare the optimal candidate of each tableau in (6) with the output which would result if the bottom four constraint of (11) are ranked in the Pre-Classical and Late Latin fashion, that is we take into account syncope and shortening. In (12) a syncopated vowel is indicated by placing angled brackets around the syllable and a shortened vowel by '-'. 


\begin{tabular}{|c|c|c|c|c|c|}
\hline \multicolumn{2}{|l|}{ (12) } & $\begin{array}{l}\stackrel{\overbrace{}}{x} \\
z \\
\underset{*}{\not}\end{array}$ & $\sum_{*}^{\#}$ & $\frac{0}{3}$ & 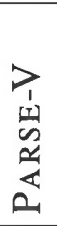 \\
\hline \multirow[t]{2}{*}{ a. /HL/ } & 棵 $(\underline{\mathrm{H}}) \mathrm{L}$ & & & & \\
\hline & $(\underline{\mathrm{H}})\langle\mathrm{L}\rangle$ & & & & $* !$ \\
\hline \multirow[t]{2}{*}{ b. $/ \mathrm{LH} /$} & $(\underline{\mathrm{LH}})$ & & $* !$ & $*$ & \\
\hline & 吗 $(\underline{\mathrm{LH}}-)$ & & & & \\
\hline \multirow[t]{2}{*}{ c. $/ \mathrm{HH} /$} & $(\underline{\mathrm{H}}) \mathrm{H}$ & & $* !$ & * & \\
\hline & $(\underline{\mathrm{H}}) \mathrm{H}-$ & & & & \\
\hline \multirow[t]{4}{*}{ d. /HLH/ } & $(\underline{\mathrm{HL}}) \mathrm{H}$ & $* !$ & $*$ & $*$ & \\
\hline & ( $\underline{\mathrm{HL}}) \mathrm{H}-$ & *! & & & \\
\hline & $(\underline{\mathrm{H}})\langle\mathrm{L}\rangle \mathrm{H}^{-}$ & & & & $*$ \\
\hline & $(\underline{\mathrm{H}})\langle\mathrm{L}\rangle \mathrm{H}$ & & $*$ ! & $*$ & $*$ \\
\hline \multirow[t]{2}{*}{ e. /HLL/ } & ( & $* !$ & & & \\
\hline & 俚 $(\underline{\mathrm{H}})\langle\mathrm{L}\rangle \mathrm{L}$ & & & & $*$ \\
\hline
\end{tabular}

In tableau (12a) the optimal output is similar to the first one in tableau (6a). This difference is one of the reasons why syncope is formulated as a foot-based constraint. The surfacing of the final light syllable in (12a) does not violate the syncope constraint. If syncope were reformulated as post-stress vowel deletion, the second form in (12a) would be the optimal one.

Syncope is also correctly predicted to apply in \#LLo\# words and to pre-tonic LL feet, as in sol $\langle i\rangle d u$ s or cal $\langle e\rangle$ facere, respectively (cf. (2) above). In (13) we have provided tableaux showing the optimal parse for solidus. We have left the constraint $*(\mathrm{HL})$ out of consideration. 


\begin{tabular}{|c|c|c|c|c|c|}
\hline (13) /LLH/ & 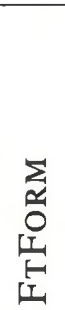 & 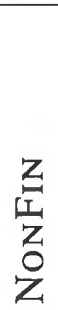 & 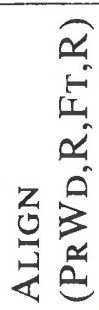 & $\frac{\overrightarrow{2}}{3}$ & 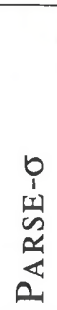 \\
\hline$(\underline{\mathrm{L}}) \mathrm{L} \mathrm{H}$ & $* !$ & & $\sigma \sigma !$ & * & $* *$ \\
\hline$(\underline{\mathrm{LL}}) \mathrm{H}$ & & & $\sigma$ & $*$ & $*$ \\
\hline $\mathrm{L}(\underline{\mathrm{LH}})$ & & $* !$ & & $*$ & $*$ \\
\hline$(\underline{\mathrm{L}}) \mathrm{L}(\underline{\mathrm{H}})$ & *! & $*$ & & & $*$ \\
\hline$(\underline{\mathrm{L}})(\underline{\mathrm{LH}})$ & $* !$ & * & & $*$ & \\
\hline$(\mathrm{LL})(\underline{\mathrm{H}})$ & *! & * & & & \\
\hline
\end{tabular}

In (14) we have again compared the optimal candidate of (13) with other possible candidates under the syncope-shortening constraint ranking.

\begin{tabular}{|l||c|c|c|c|}
\hline$(14) / \mathrm{LLH} /$ & $* \mathrm{~V}$ IN $(\mathrm{x})$. & $* \mathrm{VV} \#$ & WSP & PARSE-V \\
\hline \hline$(\underline{\mathrm{LL}}) \mathrm{H}$ & $* !$ & & $*$ & \\
\hline$(\underline{\mathrm{L}} \mathrm{L}\rangle \mathrm{H})=(\mathrm{H}) \mathrm{H}$ & & & $*$ & $*$ \\
\hline
\end{tabular}

It should be noticed that the application of syncope transforms the first syllable in solidus into a heavy one, as indicated in (14) which again shows that exhaustive parsing is not the motivating force behind syncope. The two light syllables in the optimal output in (13) as well as the remaining syllable in the optimal output in (14) are both perfect feet.

Let us summarize the discussion so far: the inclusion of the uneven trochee as a possible foot resulting from constraint interaction permitted us to straightforwardly identify the foot with main stress in all cases, viz. the last foot. Moreover, the uneven trochee allowed a straightforward account of the cases where syncope did apply, which was impossible both under Mester's account and under the OT-account provided by Prince and Smolensky. The reason why the uneven trochee cannot 
be accepted as a primitive foot type will not be dealt with here, but can be demonstrated on the basis of Latin enclitic stress (cf. Jacobs 1997).

There is one last problem to deal with. Syncope is, contrary to fact, predicted to apply in LL- and LH-words. Let us consider again (12b), where we have left one output candidate out of consideration. After vowel shortening, syncope should apply to the foot (LH-). That is, an output candidate $(\mathrm{H})$ should be optimal. We cannot relate the non-application of syncope to a violation of undominated FTBIN, given that the initial light syllable will become a heavy one. Tableau (15) illustrates this for possible output candidates for an LH input, such as ămō.

\begin{tabular}{|c||c|c|c|c|}
\hline (15) /ămō/ & *V IN (X .) & $* V V \#$ & WSP & PARSE-V \\
\hline \hline$(\underline{a} \mathrm{a})\langle\mathrm{o}\rangle$ & & & & $*$ \\
\hline$(\underline{a} \mathrm{a} \overline{0})$ & $* !$ & $*$ & $*$ & \\
\hline$(\underline{a} \mathrm{a}$ ŏ $)$ & $* !$ & & & \\
\hline
\end{tabular}

There are two possible ways of preventing syncope from applying in these cases. One would be, much in the same way as phonotactic constraints ${ }^{2}$ that govern the application of syncope, to assume that a highranked constraint demands that the final syllable must remain intact as it conveys important morphological information (case, number, gender etc.). A second more direct way would be to assume that the constraint FTBIN is not an undominated constraint, but, in fact, is dominated by NonFInALITY. This will have the effect of not grouping together into one foot the two syllables of LL- and LH-words. This is illustrated in (16). 


\begin{tabular}{|c|c|c|c|c|c|}
\hline (16) & $\begin{array}{l}Z \\
\text { Z⿱ } \\
Z \\
\text { Zn } \\
\mathbf{Z} \\
\end{array}$ & 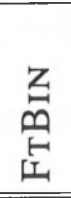 & 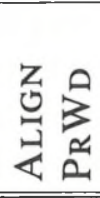 & $\frac{0}{3}$ & 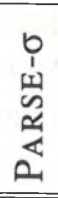 \\
\hline b. $\quad$ /LH/ $\quad(\underline{\mathrm{LH}})$ & $* !$ & & & \% & \\
\hline$(\underline{\mathrm{L}}) \mathrm{H}$ & & $*$ & $\sigma$ & $*$ & $*$ \\
\hline $\mathrm{L}(\underline{\mathrm{H}})$ & $* !$ & & & & $*$ \\
\hline a. $\quad / \mathrm{LL} / \quad(\underline{\mathrm{LL}})$ & $* !$ & & & & \\
\hline$(\underline{\mathrm{L}}) \mathrm{L}$ & & $*$ & $\sigma$ & & $*$ \\
\hline $\mathrm{L}(\underline{\mathrm{L}})$ & $* !$ & & & & $*$ \\
\hline
\end{tabular}

The non-application of syncope to LL- and LH-words follows automatically from the constraint hierarchy, given that the final syllable is not part of the foot.

\section{Summary}

In this paper we have modified Prince and Smolensky's OT account of Latin stress. We have shown that their analysis had two main problems. On the one hand, reference must be made to the foot with main stress in the constraint NonFinALITY, which as we have shown predicts the existence of nonexisting quarternary stress systems. Second, the analysis could not account for shortening in all cases nor could it account for syncope in LL-sequences.

We have argued that the simplification of NoNFINALITY and the inclusion of the uneven trochee as a foot type resulting from constraint interaction allowed a straightforward analysis of Latin main stress, without leading to unwanted typological predictions. Furthermore, we have shown that simplifying NONFINALITY and allowing the constraint *(HL) to be dominated (the uneven trochee) was independently needed to provide a straightforward account of the cases where syncope did apply. 


\section{Notes}

1. There is a striking directional asymmetry in previous foot-extrametricality. It typically only occurs in rightward (when footing is from left-to-right), but not in leftward stress systems. As shown in Jacobs (1999), NonFInAlity as modified here directly explains the asymmetry.

2. In Classical Latin, syncope is clearly subject to phonotactic constraints. The output is always compatible with the phonotactic constraints of the langue, a situation which changes in Late Latin. In this article we will not go into the details.

\section{References}

Benloew, Louis

1847 De l'accentuation dans les langues indo-européennes tant anciennes que modernes. Paris: Hachette.

Hayes, Bruce

1995 Metrical Stress Theory: Principles and Case Studies. Chicago: University of Chicago Press.

Jacobs, Haike

1997 Latin enclitic stress revisited. Linguistic Inquiry 28: 648-661.

1999 Constraining constraints: NonFinaLiTy and the typology of footextrametricality. Linguistics in the Netherlands 1999, 111-120. Amsterdam/Philadelphia: John Benjamins.

Kager, René

1997 Rhythmic vowel deletion in optimality theory. In: I. Roca (ed.), Derivations and Constraints in Phonology, 463-499. Oxford: Oxford University Press.

1999 Optimality Theory: A Textbook. Cambridge: Cambridge University Press.

Lahiri, Aditi, Tomas Riad and Haike Jacobs

1999 Diachronic prosody. In: Harry van der Hulst (ed.), Word Prosodic Systems in the Languages of Europe, 335-422. Berlin: Mouton de Gruyter.

Lindsay, Wallace

1894 The Latin Language (2nd edition). New York/London: Hafner.

[1963]

Loehken, Silvia

1997 Deutsche Wortprosodie. Abschwächungs- und Tilgungsvorgänge. (Studien zur deutschen Grammatik 56.) Tübingen: Stauffenburg Verlag.

McCarthy, John and Alan Prince

1993 Generalized alignment. Yearbook of Morphology, 79-153. 
Mester, Armin

1994 The quantitative trochee in Latin. Natural Language and Linguistic Theory 12: 1-61.

Niedermann, Max

1931 Phonétique historique du latin. 2nd edn. Paris: Klincksieck.

Prince, Alan and Paul Smolensky

1993 Optimality Theory: Constraint Interaction in Generative Grammar. Technical Report 2, Center for Cognitive Sciences, Rutgers University, New Brunswick, N.J., and Computer Science Department, University of Colorado, Boulder. 